\title{
Photo-Initiated Cross-Linking of a Methacrylate/Ionic Liquid Based Gel Polymer Electrolyte: Effect of the Curing Sequence on the Electrochemical Properties
}

H. Porthault $, *, \uparrow$ G. Piana $, \uparrow, \ddagger$ M. Cesbron,$\uparrow$ V. Armel,$\uparrow$ A. Bazin,$\uparrow$ S. Franger,$\uparrow$ and S. Oukassi $\uparrow$

†Univ. Grenoble Alpes, CEA, LETI, MINATEC Campus, 38054 Grenoble, France

$\$$ Institut de Chimie Moléculaire et des Matériaux d'Orsay, Univ. Paris-Sud XI, Orsay, France

*corresponding author: helene.porthault@cea.fr

\section{Supporting Information}

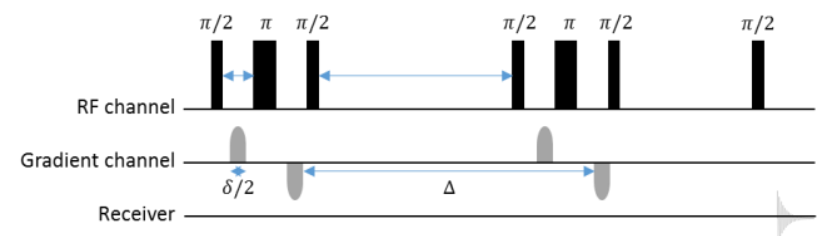

Figure S1: PFG NMR pulse sequence used to measure self-diffusion coefficients.

\begin{tabular}{ccccc}
\hline & $T_{l}(m s)$ & $\mathrm{P}_{1}(\mu \mathrm{s})$ & $\Delta(\mathrm{ms})$ & $\delta(\mathrm{ms})$ \\
\hline${ }^{1} \mathrm{H}$ & 860 & 9.5 & 400 & 10 \\
${ }^{19} \mathrm{~F}$ & 450 & 19.5 & 400 & 10 \\
${ }^{7} \mathrm{Li}$ & 340 & 9.3 & $600-800$ & $15-20$ \\
\hline \multicolumn{4}{l}{ Table S1: Sequence parameters for the PFG-NMR spectroscopy at $60{ }^{\circ} \mathrm{C}}$.
\end{tabular}




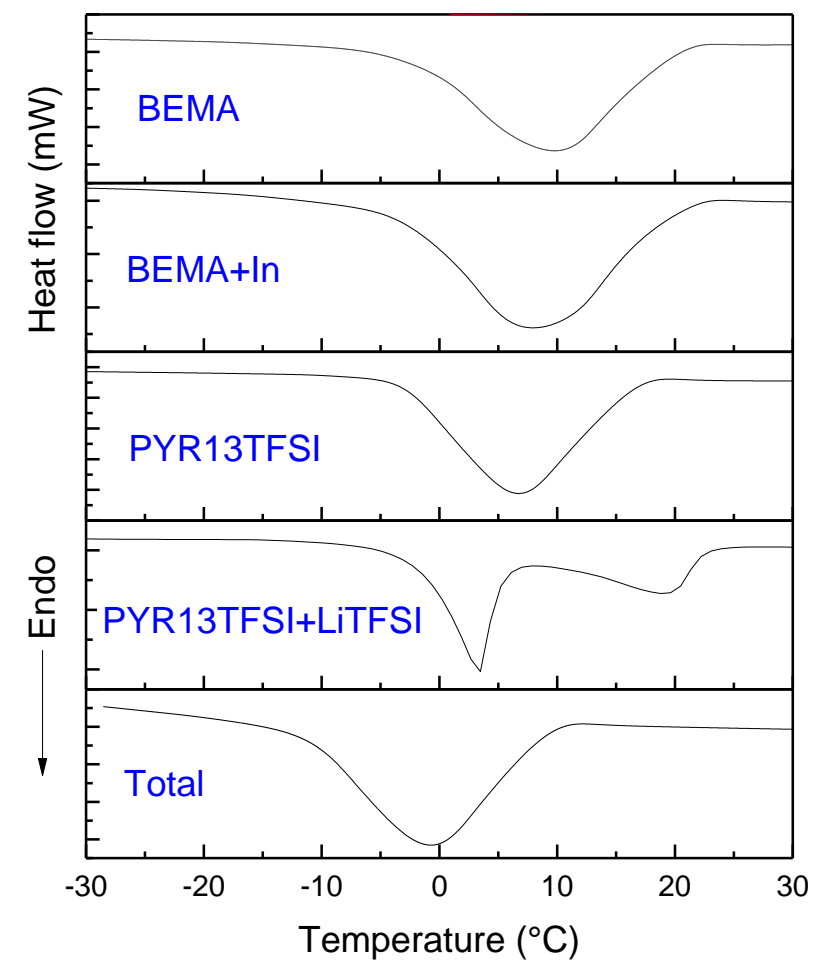

Figure S2: DSC thermograms of pristine components and total precursor solution before any irradiation.

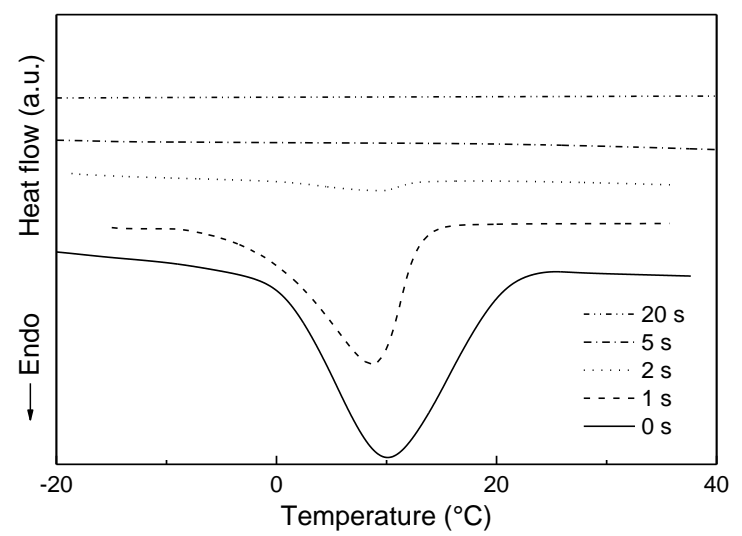

Figure S3: DSC thermograms of the neat BEMA at various irradiation times for $32 \mathrm{~mW} . \mathrm{cm}^{-2}$. 


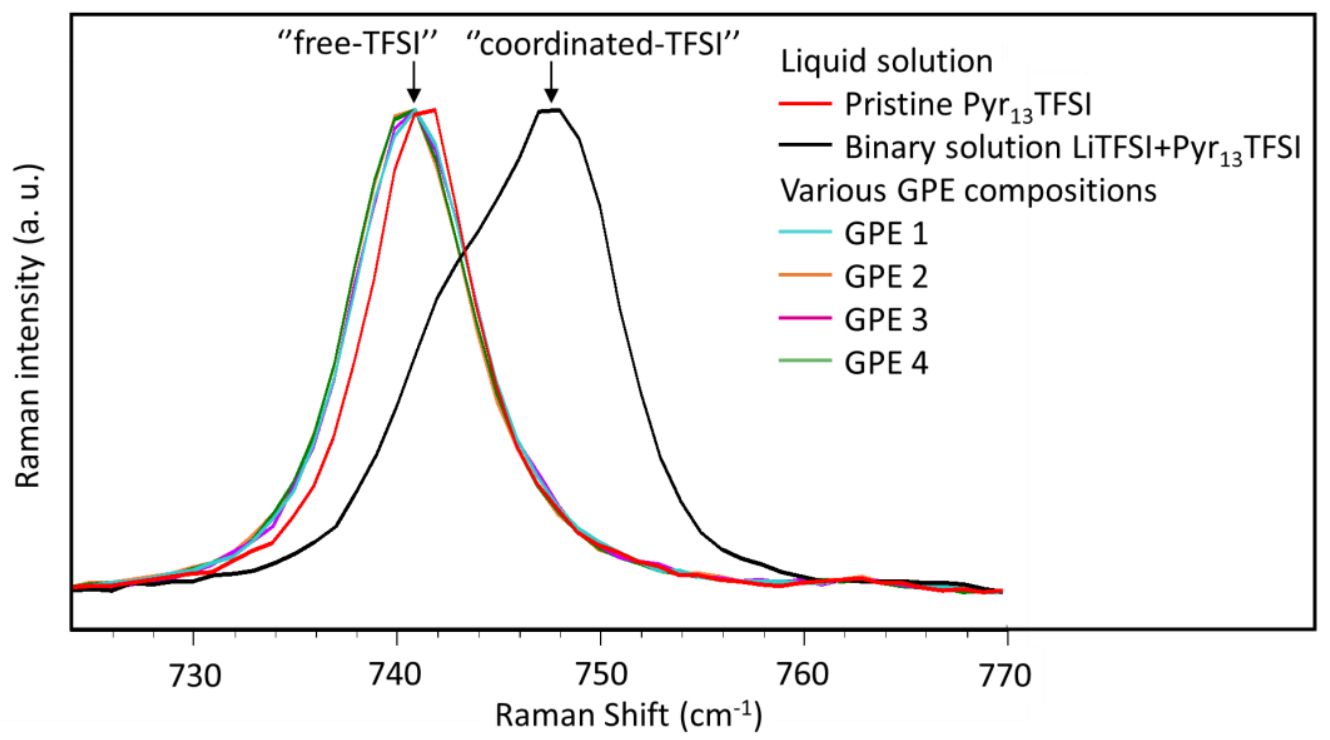

Figure S4: Raman spectra of liquid solutions (neat ionic liquid and ionic liquid + Li salt) and various GPE compositions cured at $3 \mathrm{~mW} . \mathrm{cm}^{-2}$ showing the evolution of "coordinated-TFSI' and 'free-TFSI" peaks.

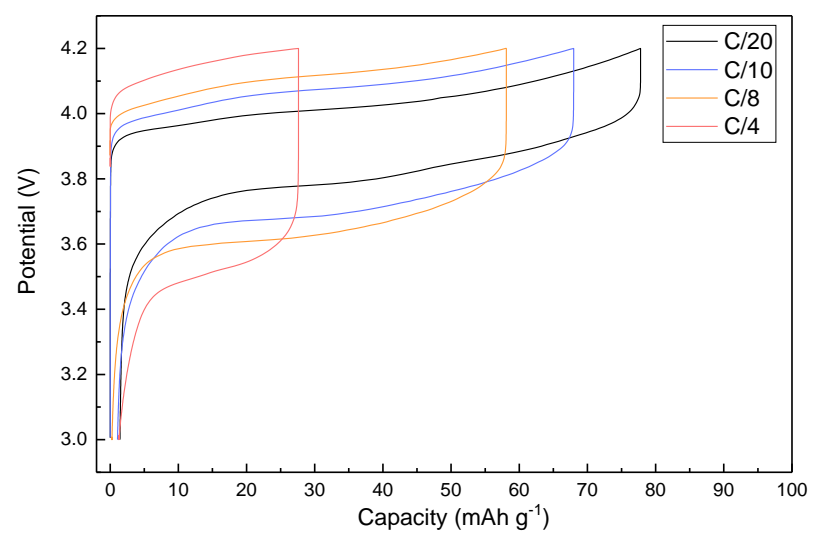

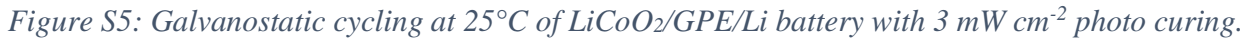

